\title{
Vegetation Cover Change and Relative Contributions of Associated Driving Factors in the Ecological Conservation and Development Zone of Beijing, China
}

\author{
Linlin Cheng, Ye Zhang*, Haiyuan Sun \\ College of Geoscience and Surveying Engineering, China University of Mining and Technology (Beijing), China
}

Received: 17 August 2018

Accepted: 27 December 2018

\begin{abstract}
The ecological conservation and development zone of Beijing (ECDZB) was set as an ecological and water source protection barrier for Beijing in 2005. Vegetation cover can reflect the conditions of the ecological environment, and the main factors that influence vegetation cover are climate change and human activities. In this study, remote sensing and meteorological data from 2001-2015 were used to analyze the spatiotemporal changes in vegetation cover in the ECDZB as well as their correlations with precipitation and temperature. Moreover, the relative contributions of climate change and human activities were quantitatively evaluated via residual analyses. The results showed that the annual maximum value of the Normalized Difference Vegetation Index (NDVI) in the ECDZB increased in general. Furthermore, the annual maximum NDVI was positively correlated with the annual precipitation and negatively correlated with the mean annual temperature. Moreover, the relative contribution rate of human activities to NDVI changes was $59.66 \%$, which was higher than the $40.34 \%$ attribution of climate change. These results indicated that human activities dominated the process of vegetation cover change in the ECDZB, and the establishment of the ECDZB has played a crucial role in improving the regional ecological environment.
\end{abstract}

Keywords: driving factors, Normalized Difference Vegetation Index, ecological conservation and development zone of Beijing, relative contribution

\section{Introduction}

Vegetation plays an important role in terrestrial ecosystems [1], which not only directly provide the necessary living conditions for human beings but

*e-mail: Zhangy_cumtb@163.com also link the material circulation and energy flow among the pedosphere, hydrosphere and atmosphere; moreover, the vegetation in terrestrial ecosystems has an irreplaceable influence on maintaining global climate stability and ecosystem balance [2]. The dynamic changes in vegetation can reflect the situation of the regional ecological environment [3-4], and the main factors that affect changes in vegetation are human 
activities and climate factors, such as temperature and precipitation [5-6]. Therefore, monitoring the variation in vegetation cover and quantitatively analyzing the relative contributions of climate change and human activities to the process of vegetation change are of great significance to regional ecological environmental protection and responses to global climate change [7-8].

The normalized difference vegetation index (NDVI) can objectively reflect the cover and growth status of vegetation on a large scale [9] and is widely used for detecting vegetation changes in different scenarios $[2$, 10-11]. In recent years, numerous case studies have been conducted to analyze the vegetation change and the relevant driving factors at regional or global scales [1215]. For example, Faramarzi et al. [16] created the NDVI maps of 1986, 2001, and 2013 to evaluate the vegetation change in a semiarid rangeland in western Iran, and the authors found that the amount of precipitation seemed to be one of the most important factors that affected the vegetation in the study area. Leroux et al. [17] successfully combined vegetation trend analysis with land use and land cover change (LULCC) studies to analyze the driving force of the biomass production changes that were represented by the NDVI. Muriithi et al. [18] investigated the trends in the average annual NDVI before and after the presumed onset of rapid horticulture in the central highlands of Kenya, and the authors further analyzed the relationship between the average annual NDVI and specific driving factors, such as population density, large-scale commercial farms, and mean annual rainfall in sub-watersheds. It can be seen that international scholars are devoting more attention to the influence of climatic factors and human activities on vegetation changes, and some studies have indicated that ecological construction projects have greatly influenced vegetation changes [19-21]. However, most of these studies have focused only on qualitative descriptions; thus, it is necessary to quantitatively analyze the relative contributions of climate change and human activities to changes in vegetation [22].

As a cosmopolitan city, Beijing's coordinated development of the economy and the ecological environment is very important. To further implement the view of scientific development and implement the "Overall Planning of Beijing City (2004-2020)", the municipal party committee and the municipal government of Beijing proposed guiding opinions on the evaluation index and the function positioning of the district and county in 2005. To further clarify the functional orientation of districts and counties, the guiding opinions separate the entire city into four categories: the capital functional core area, the urban function expansion area, the urban development new area and the ecological conservation development area; this categorization is based on the tentative plan of "two axes - two bands - multi centers" and the principle of "optimizing the urban areas and strengthening the suburbs". Among these categories, the ecological conservation and development zone of
Beijing (ECDZB) is delimited according to a number of factors, such as the resource environment carrying capacity, current exploitation intensity and future exploitation potential [23], and the primary objectives are to strengthen the protection and construction of the ecological environment, guide the relative gathering of the population, guide the rational development and utilization of natural resources, develop eco-friendly industries, and provide a solid ecological barrier for Beijing and an ideal space for citizens to enjoy leisure activities. There are five districts that constitute the ECDZB, including Mentougou, Pinggu, Huairou, Miyun and Yanqing. Mountainous and shallow mountainous areas occupy most of the ECDZB, specifically, the mountainous area covers more than $62 \%$ of the area. Additionally, the ECDZB plays a significant role in Beijing's sustainable development, and it is seen as an ecological conservation and water source protection area of Beijing.

In recent years, studies on the ECDZB have mainly focused on industrial development and policy measures [24-25]. He et al. [26] conducted in-depth research and made specific recommendations related to rural tourism in the ECDZB. Zhang [27] subdivided the ECDZB into four sub-regions and proposed specific construction tasks and policy recommendations for each subregion. However, there have been few studies related to the vegetation cover change and the related driving factors in the ECDZB. Therefore, this study attempts to gain a better understanding of the effect of the ECDZB's establishment; specifically, this study assesses whether the establishment has had a positive impact on the ecological environment of the ECDZB from the perspective of the changes in vegetation cover. Based on a combination of the moderate-resolution imaging spectroradiometer (MODIS) NDVI dataset, temperature data, and precipitation data of the ECDZB from 2001 to 2015 , this paper analyzed the characteristics and trends of NDVI variations in the study area; then, the authors further separated and quantitatively analyzed the influence of climate change and human activities on changes in vegetation by using partial correlation analysis and residual analysis methods.

\section{Materials and Methods}

\section{Study Area}

The ECDZB (Fig. 1) is located in the northern and western parts of Beijing $\left(39^{\circ} 48^{\prime}-41^{\circ} 04^{\prime} \mathrm{N}\right.$, $\left.115^{\circ} 25^{\prime}-117^{\circ} 30^{\prime} \mathrm{E}\right)$ and covers an area of approximately $8746.65 \mathrm{~km}^{2}$, which accounts for $53.30 \%$ of the city's total area. The landforms in the study area are relatively uniform, and they primarily include mountainous areas and shallow mountainous areas. The climate in the ECDZB is the typical north temperate zone semi-humid continental monsoon climate, which has four distinct seasons. The distribution of annual 


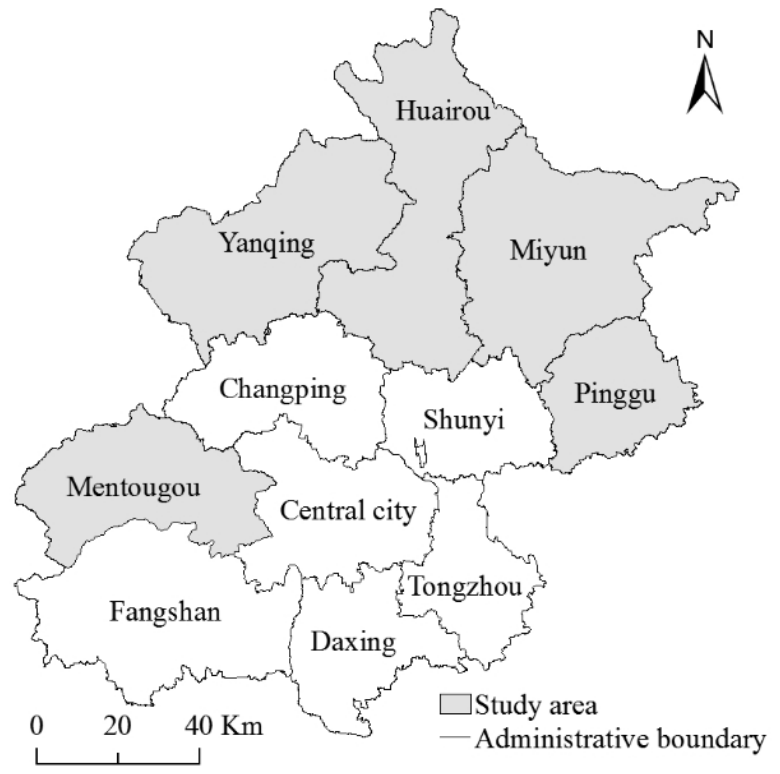

Fig. 1. Location of the ecological conservation and development zone of Beijing.

precipitation is usually uneven and mostly occurs in June, July, and August. The average annual amount of precipitation in the ECDZB is approximately $450 \sim 670 \mathrm{~mm}$, and the annual average temperature is approximately $10 \sim 12^{\circ} \mathrm{C}$. The vegetation resources of the ECDZB are abundant with diverse vegetation types, and the main types include warm temperate deciduous broad-leaved forests and temperate coniferous forests.

\section{Data Source and Processing}

The NDVI dataset used in this study is the MOD13Q1 product provided by the National Aeronautics and Space Administration (NASA) (https:// lpdaac.usgs.gov). The data was taken at 16-day intervals with a spatial resolution of $250 \mathrm{~m} \times 250 \mathrm{~m}$. Since the MODIS NDVI dataset was not available until the $49^{\text {th }}$ day in 2000 and the ECDZB was not established until 2005, we chose data between 2001 and 2015 to analyze the impact of the ECDZB's establishment on vegetation cover to ensure that the data were more consistent and the results were more reliable. The MODIS Reprojection Tool (MRT), also provided by NASA, was used to process the data, and the processing included format and projection conversions, image mosaic and clipping. Monthly and annual NDVI values were acquired using the maximum value composite (MVC) method, which minimizes the influence of some clouds, atmosphere, and solar elevation angles to make the data more reliable [28].

Monthly average temperature and monthly precipitation datasets for the period between 2001 and 2015 from 30 meteorological stations in and around the ECDZB were obtained from the China Meteorological
Data Service Center (http://data.cma.cn/en). The kriging interpolation method was used on the meteorological data to obtain the raster dataset, which has the same resolution as the NDVI dataset; then, we extracted the dataset according to the ECDZB's boundary and calculated the values of the annual average temperature and annual cumulative precipitation datasets to prepare for the analysis that followed.

To perform a thorough investigation, we also used auxiliary data for the analysis of the relationships between the NDVI and the associated driving factors. The land cover data of the ECDZB in 2010 was derived from the GlobeLand30-2010, which was launched by the National Geomatics Center of China (http://www. globallandcover.com/GLC30Download/index.aspx). The development, protection, control and construction of the Beijing mountainous area guide plan map came from the Beijing Municipal Institute of City Planning and Design (BICP) [29].

\section{Methods}

\section{Analysis of Trends in Annual Maximum NDVI}

By using the linear regression method during the study period, the slope of the linear regression reflects the trend in the vegetation changes for each pixel, and the spatiotemporal variation characteristics of vegetation can be analyzed comprehensively [30-31]. Thus, the variation in the annual maximum NDVI in the ECDZB was analyzed using the method mentioned above. The slope is calculated as follows:

$$
\text { Slope }=\frac{n \times \sum_{i=1}^{n}\left(i \times N D V I_{i}\right)-\sum_{i=1}^{n} i \sum_{i=1}^{n} N D V I_{i}}{n \times \sum_{i=1}^{n} i^{2}-\left(\sum_{i=1}^{n} i\right)^{2}}
$$

...where Slope is the trend in vegetation changes, $n$ is the cumulative number of years in the study period, $i$ is the order of year in the study period, and $N D V I_{i}$ is the maximum NDVI in the $i$ th year. The NDVI shows an increasing trend when Slope $>0$ and a decreasing trend when Slope $<0$.

\section{Correlation Analysis of NDVI and Climate Factors}

There are many factors that influence the change in vegetation cover, and partial correlation analysis can measure only the linear correlation between the NDVI and one specific factor, while the influences of the other factors are excluded [32]. In this paper, the correlation coefficients of the annual maximum NDVI and the climate factors, including the mean annual temperature and annual precipitation, were calculated for each pixel to estimate the partial correlation coefficients. The correlation coefficient is calculated as follows: 


$$
r_{x y}=\frac{\sum_{i=1}^{n}\left(x_{i}-\bar{x}\right)\left(y_{i}-\bar{y}\right)}{\sqrt{\sum_{i=1}^{n}\left(x_{i}-\bar{x}\right)^{2} \sum_{i=1}^{n}\left(y_{i}-\bar{y}\right)^{2}}}
$$

...where $r_{x y}$ is the correlation coefficient for $x$ and $y, n$ denotes the cumulative number of years in the study period, $x_{i}$ refers to the maximum NDVI in the $i$ th year, $y_{i}$ is the mean annual temperature or the annual precipitation in the $i$ th year, and $\bar{x}$ and $\bar{y}$ are the average values of $x$ and $y$, respectively.

The formula for the partial correlation analysis is as follows:

$$
r_{x y, z}=\frac{r_{x y}-r_{x z} r_{y z}}{\sqrt{\left(1-r_{x z}^{2}\right)\left(1-r_{y z}^{2}\right)}}
$$

...where $r_{x y, z}$ is the partial correlation coefficient between the variables $x$ and $y$, with variable $z$ as the control variable; $r_{x y}, r_{x z}$, and $r_{y z}$ stand for the correlation coefficients between variables $x$ and $y$, variables $x$ and $z$, and variables $y$ and $z$, respectively. The partial correlation coefficient provides a value between +1 and -1 , where the variables $x$ and $y$ have a positive correlation when $r_{x y, z}>0$ and a negative correlation when $r_{x y, z}<0$ (with variable $z$ being the control variable). The significance tests of the partial correlation coefficients were conducted by $t$ test.

\section{Analysis of the Respective Effects of Climate and Humans on Vegetation Cover Change}

The residual analysis method proposed by Evans and Geerken [33] in 2004 was considered to be robust and has been widely accepted to separate the effects of climate change and human activities on vegetation cover change [17]. Based on the residual analysis method, we established the multiple regression models of the NDVI, temperature and precipitation for every pixel in order to obtain the predictive value of the NDVI $\left(\mathrm{NDVI}_{\mathrm{p}}\right)$, which is regarded as the influence of the climatic factors on the changes in the NDVI. The residuals between the observed NDVI $\left(\mathrm{NDVI}_{\mathrm{O}}\right.$ ) and $\mathrm{NDVI}_{\mathrm{p}}$ can be regarded as the influence of human activities on the changes in NDVI [34]. The residual analysis expression is as follows:

$$
N D V I_{R}=N D V I_{O}-N D V I_{P}
$$

...where $\mathrm{NDVI}_{\mathrm{R}}$ is the residual value that represents a positive influence of human activities on the changes in the NDVI when $\mathrm{NDVI}_{\mathrm{R}}>0$, and a negative influence when $\mathrm{NDVI}_{\mathrm{R}}<0$.

\section{Analysis of Relative Contributions}

The relative contributions of climate change and human activities on the processes related to changes in the NDVI were calculated by using the ideas and methods proposed by Sun et al. [35] in 2015. Based on a combination of the $\mathrm{NDVI}_{\mathrm{O}}$ and the positive or negative trends of the $\mathrm{NDVI}_{\mathrm{P}}$ and $\mathrm{NDVI}_{\mathrm{R}}$, the calculation methods for the relative contributions were built under different scenarios, as shown in Table 1.

\begin{tabular}{|c|c|c|c|c|c|c|}
\hline Zone types & Scenarios & $\begin{array}{c}\text { Slope } \\
\left(\mathrm{NDVI}_{\mathrm{p}}\right)\end{array}$ & $\begin{array}{c}\text { Slope } \\
\left(\mathrm{NDVI}_{\mathrm{R}}\right)\end{array}$ & $\begin{array}{l}\text { Relative contribution of } \\
\text { climate variations } / \%\end{array}$ & $\begin{array}{l}\text { Relative contribution of } \\
\text { human activities } / \%\end{array}$ & Explanation \\
\hline \multirow{3}{*}{$\begin{array}{l}\text { Zone of } \\
\text { vegetation } \\
\text { increase }\end{array}$} & Scenario1 & $>0$ & $>0$ & $\frac{\text { Slope }\left(N D V I_{P}\right)}{\text { Slope }\left(N D V I_{O}\right)} \times 100$ & $\frac{\text { Slope }\left(N D V I_{R}\right)}{\text { Slope }\left(N D V I_{O}\right)} \times 100$ & $\begin{array}{l}\text { Both climate variations and } \\
\text { human activities led to the } \\
\text { vegetation increase. }\end{array}$ \\
\hline & Scenario 2 & $>0$ & $<0$ & 100 & 0 & $\begin{array}{c}\text { Climate variations led to the } \\
\text { vegetation increase. }\end{array}$ \\
\hline & Scenario 3 & $<0$ & $>0$ & 0 & 100 & $\begin{array}{c}\text { Human activities led to the } \\
\text { vegetation increase. }\end{array}$ \\
\hline \multirow{3}{*}{$\begin{array}{l}\text { Zone of } \\
\text { vegetation } \\
\text { decrease }\end{array}$} & Scenario 1 & $<0$ & $<0$ & $\frac{\operatorname{Slope}\left(N D V I_{P}\right)}{\operatorname{Slope}\left(N D V I_{O}\right)} \times 100$ & $\frac{\text { Slope }\left(N D V I_{R}\right)}{\operatorname{Slope}\left(N D V I_{O}\right)} \times 100$ & $\begin{array}{l}\text { Both climate variations and } \\
\text { human activities led to the } \\
\text { vegetation decrease. }\end{array}$ \\
\hline & Scenario 2 & $<0$ & $>0$ & 100 & 0 & $\begin{array}{c}\text { Climate variations led to the } \\
\text { vegetation decrease. }\end{array}$ \\
\hline & Scenario 3 & $>0$ & $<0$ & 0 & 100 & $\begin{array}{l}\text { Human activities led to the } \\
\text { vegetation decrease. }\end{array}$ \\
\hline
\end{tabular}

Table 1. Methods for calculating the relative contributions of climate variations and human activities to the process of vegetation cover change in different scenarios.

Note: Slope $\left(\mathrm{NDVI}_{\mathrm{P}}\right)$ is the trend of the $\mathrm{NDVI}_{\mathrm{p}}$ caused by climate variations; Slope $\left(\mathrm{NDVI}_{\mathrm{R}}\right)$ is the trend of the $\mathrm{NDVI}_{\mathrm{R}}$ caused by human activities; and Slope $\left(\mathrm{NDVI}_{\mathrm{O}}\right)$ is the trend of the observed NDVI. 


\section{Results}

Evolution Trend of Vegetation Cover and Characteristics of Climate Variations

The annual maximum NDVI of the ECDZB from 2001 to 2015 showed a general upward trend (Fig. 2a). Only the periods of 2001-2003 and 2013-2014 showed apparent downward trends, indicating that the vegetation cover in the study area had generally improved, with the exception of certain years. By analyzing temperature and precipitation data during the 15-year period in the ECDZB (Figs. $2 b$ and c), it can be seen that the annual precipitation from 2001 to 2015 in the study area presented a non-significant increasing trend and reached a maximum value in

a)

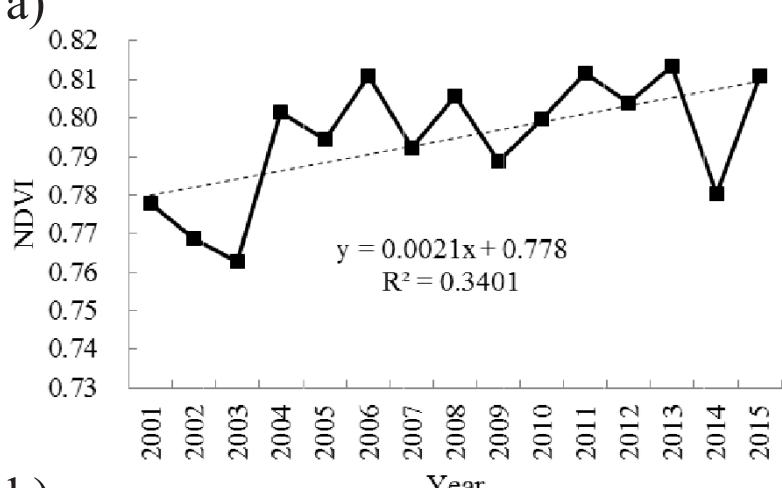

b)
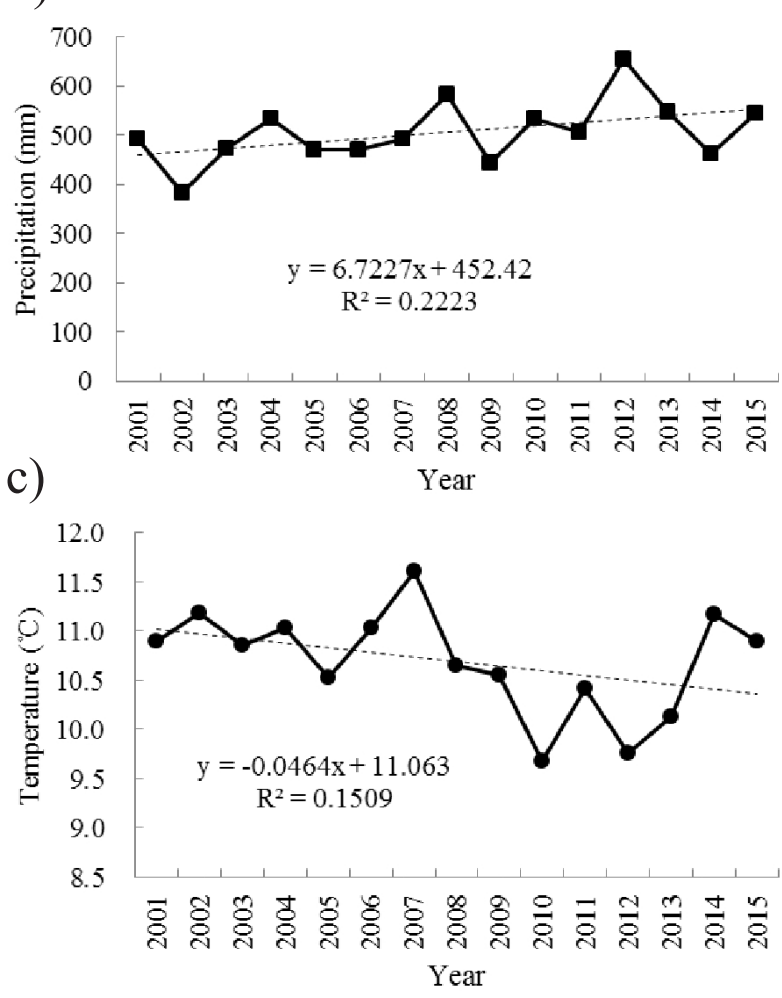

Fig. 2. Changing trends in a) annual maximum NDVI, b) annual precipitation, and c) annual average temperature in the ECDZB from 2001 to 2015.
2012. The average temperature showed a fluctuating downward trend, which reached its lowest values in 2010 and 2012.

To further analyze the spatial distribution of the annual maximum NDVI, we averaged the annual maximum NDVI for 15 years in the study area to obtain the NDVI spatial distribution map of the ECDZB for the period of 2001-2015 (Fig. 3). According to Fig. 3, the vegetation cover shows better conditions in the middle and northern regions of the study area as well as in the southwestern region of Mentougou District, where the land cover types appear to be mainly forest and grassland based on the land cover data (Fig. 4). In contrast, the vegetation cover was worse in the southeastern part of the study area, the southwestern part of Miyun District, the southeastern part of Huairou District, and the western part of Yanqing District, where the corresponding land cover types

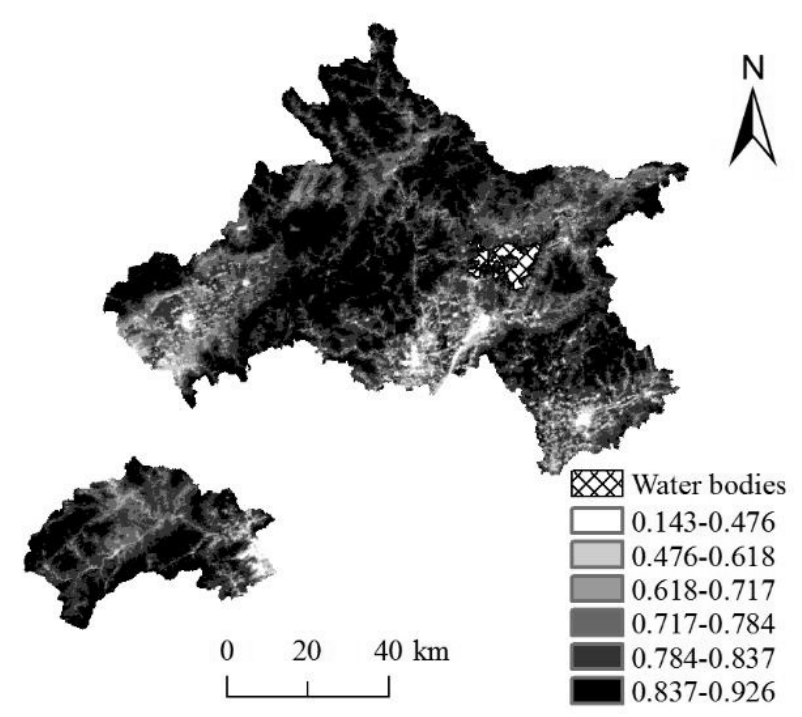

Fig. 3. Average annual maximum NDVI from 2001-2015.

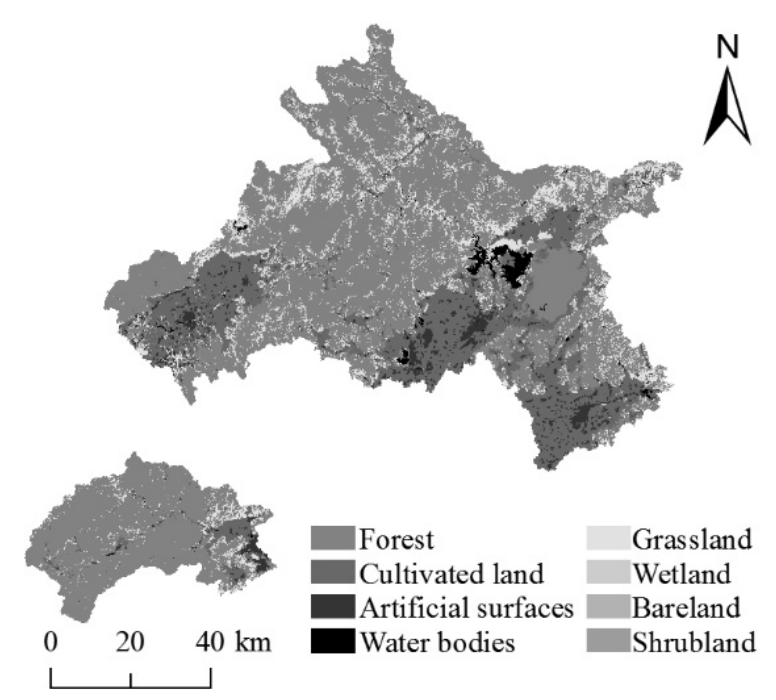

Fig. 4. Land cover types in the ECDZB. 


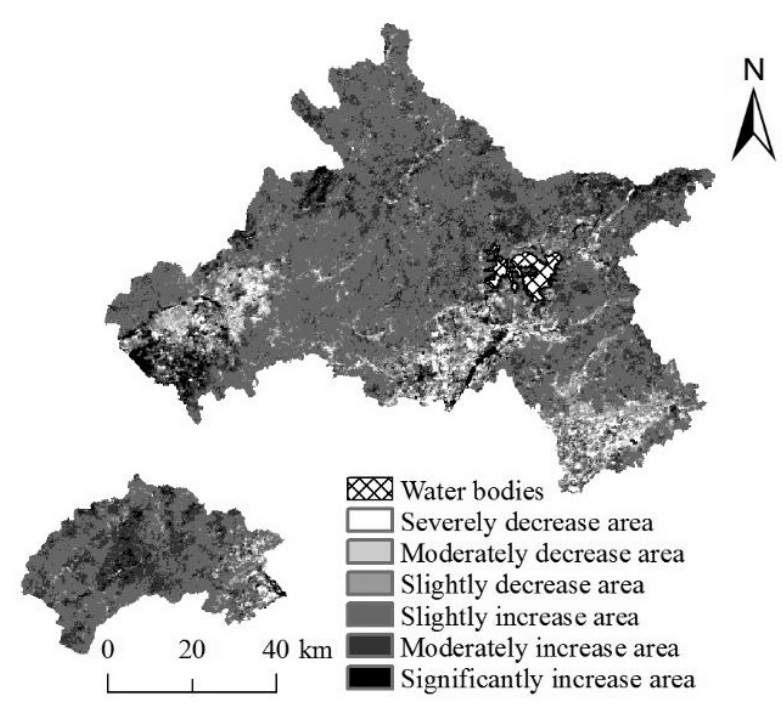

Fig. 5. Changing trends of the NDVI in the ECDZB from 2001 to 2015 .

are mainly cultivated land and artificial surfaces, with artificial surfaces encompassing all kinds of habitation, industrial and mining areas, and transportation facilities. These phenomena show that in areas where human activities are more frequent, the condition of the vegetation cover tends to be worse.

From the previous analysis, it can be seen that the annual maximum NDVI of the study area during 2001-2015 was generally increasing; however, the spatial distribution characteristics of the NDVI changes have yet to be analyzed. Therefore, the linear regression method was used to simulate the changing trends in the annual maximum NDVI for all 139,832 pixels in the ECDZB between 2001 and 2015; then, the results were reclassified into six classes using the standard deviation classification method (Fig. 5). The statistical analysis of the slope layer of the results showed that the values of Slope ranged between -0.0509 and 0.0412 , with an average value of 0.00211 ; additionally, the region where vegetation increased (where Slope $>0$ ) accounted for $82.69 \%$ of the total area, while the region of degradation (where Slope $<0$ ) accounted for $17.31 \%$, indicating that the overall vegetation cover in the study area has shown an improving trend. Table 2 lists the area percentages of the different degrees of change for the NDVI; specifically, areas where the vegetation cover slightly increased accounted for $60.98 \%$ of the total area, which was the highest among all the calculated degrees, while the proportion of the areas that were severely decreased was the lowest, at only $2.34 \%$. Fig. 5 reveals that the areas that significantly increased or moderately increased are mainly distributed in the northeastern and southwestern parts of the study area; moreover, the areas where the vegetation cover decreased are mainly concentrated in the middle of Yanqing District, southern Pinggu District, southern Huairou District, southern Miyun District and eastern Mentougou
Table 2. Proportions of different changing degrees of the NDVI in the ECDZB from 2001 to 2015.

\begin{tabular}{|c|c|c|}
\hline $\begin{array}{c}\text { Range of NDVI slope } \\
\text { changes }\end{array}$ & Degree of change & $\begin{array}{c}\text { Percent- } \\
\text { age } / \%\end{array}$ \\
\hline$-0.0509<$ Slope $\leq-0.0075$ & Severe decrease & 2.34 \\
\hline$-0.0075<$ Slope $\leq-0.0037$ & Moderate decrease & 4.13 \\
\hline$-0.0037<$ Slope $\leq 0.0000$ & Slight decrease & 10.84 \\
\hline $0.0000<$ Slope $\leq 0.0039$ & Slight increase & 60.98 \\
\hline $0.0039<$ Slope $\leq 0.0076$ & Moderate increase & 18.51 \\
\hline $0.0076<$ Slope $\leq 0.0412$ & Significant increase & 3.20 \\
\hline
\end{tabular}

District. Combined with the land cover data of the ECDZB (Fig. 4), the main land cover types of the areas that significantly and moderately increased were found to be grassland and some cultivated land in western Yanqing District; in contrast, the main corresponding type of vegetation in the slightly increased region was forest, and the areas that experienced decreases were mainly distributed in cultivated lands and artificial surfaces, which are associated with frequent human activities.

\section{Response of Vegetation Cover to Climate Change}

The results of partial correlation analysis between the annual maximum NDVI, annual precipitation, and average annual temperature over the 15 years in the study area are shown in Fig. 6. From the spatial distribution map of the partial correlation coefficients of the NDVI and precipitation (Fig. 6a), it can be seen that the annual maximum NDVI is positively correlated with the annual precipitation in most parts of the study area, and the partial correlation coefficients in the northern area are the highest; in contrast, the regions with negative correlations are mainly discretely distributed in the southeastern and northwestern parts of the ECDZB. From Fig. 6b), we can see that the regions with negative correlations between the annual maximum NDVI and the mean annual temperature are mainly located in the north and the south, while the regions in the central part of the ECDZB that are close to the central city of Beijing are mainly positively correlated. The spatial statistical analysis of the results showed that the average partial correlation coefficients of the annual maximum NDVI with the annual precipitation and average annual temperature are 0.28 and -0.10 , respectively; furthermore, the proportion of the region with a positive correlation between the annual maximum NDVI and the annual precipitation is $87.66 \%$, while the area with a negative correlation between the annual maximum NDVI and the average annual temperature accounted for $68.06 \%$. These results indicate that, overall, the annual maximum NDVI of the ECDZB 
was positively correlated with the annual precipitation during 2001-2015, and in general, the annual maximum NDVI of the ECDZB was negatively correlated with the average annual temperature. The negative correlation between the annual maximum NDVI and the mean annual temperature might due to the overly high temperatures, which may enhance surface water evaporation, strengthen plant transpiration, and further inhibit vegetation growth. The results of the $t$ test showed that the partial correlation coefficients of the annual maximum NDVI with annual precipitation and annual temperature passed the test of $\mathrm{p}<0.01$, accounting for $3.11 \%$ and $0.95 \%$, respectively; and the partial correlation coefficients that passed the test of $p<0.05$ accounted for $13.03 \%$ and $5.46 \%$, respectively. The greater the $\alpha$ values, the greater the percentage of partial correlation coefficients that pass the test of $\mathrm{p}<\alpha$.

a)

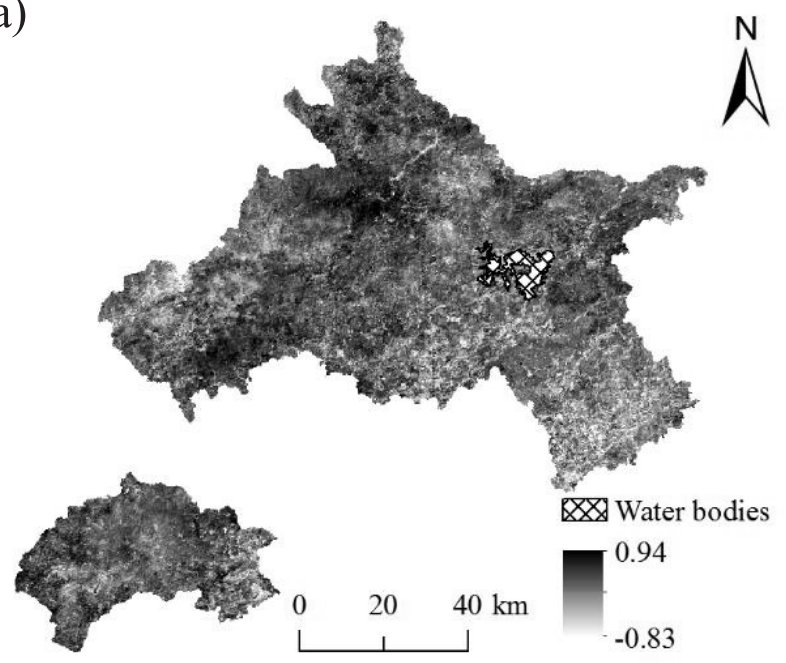

b)

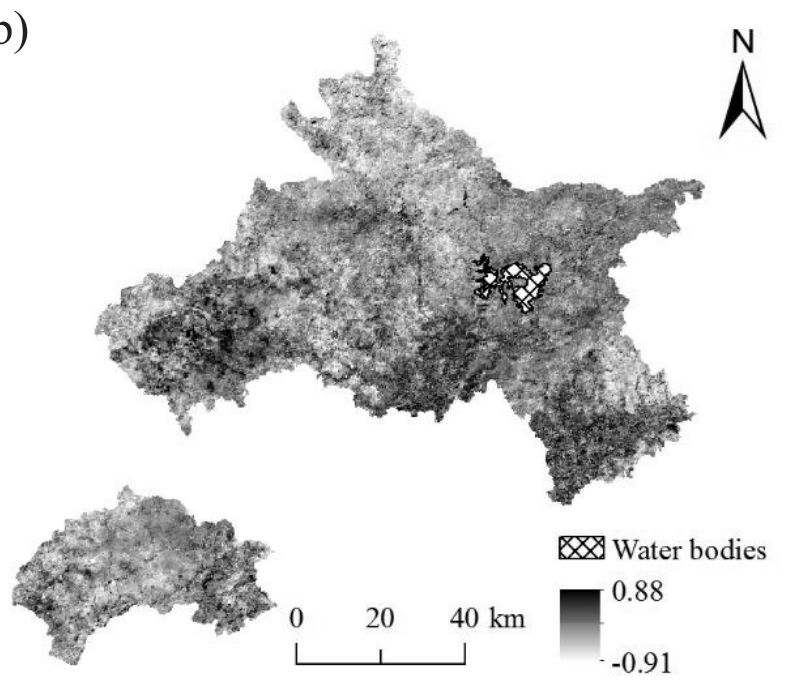

Fig. 6. Spatial distribution of the partial correlation coefficients between the a) NDVI and precipitation and b) NDVI and temperature in the ECDZB from 2001-2015.
Individual Influence of Climate Change and Human Activities on Vegetation Cover

\section{Characteristics of Vegetation Change under the Influence of Climate Change}

The residual analysis method was used to separate the effects of climate change and human activities on vegetation cover change, and based on Equation (1), the changing trend of the $\mathrm{NDVI}_{\mathrm{p}}$ from 2001 to 2015 (Fig. 7a) was obtained, and it can be interpreted as the changing trend in the NDVI under the influence of climate change. In contrast with the trends of the $\mathrm{NDVI}_{\mathrm{O}}$ changes (Fig. 5), we found that the areas with increased $\mathrm{NDVI}_{\mathrm{P}}$ were widely distributed throughout the study area and accounted for $85.65 \%$ of the total area; this value was $2.96 \%$ higher than the percentage

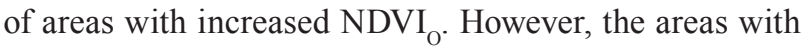
reduced $\mathrm{NDVI}_{\mathrm{p}}$ accounted for $14.35 \%$, and the spatial distribution characteristics were basically the same as those for the areas with decreased $\mathrm{NDVI}_{\mathrm{O}}$. Therefore,

a)

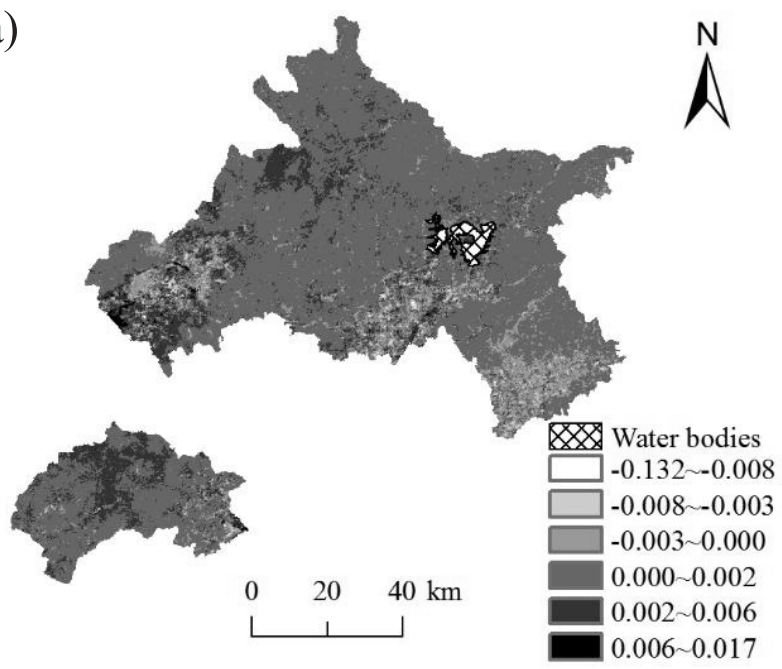

b)
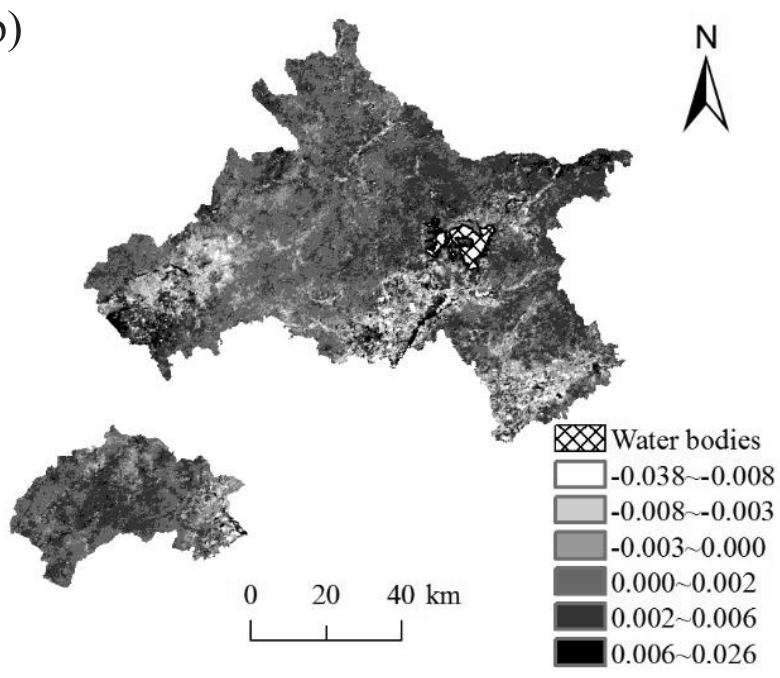

Fig. 7. Spatial distribution of the trends for the a) NDVI under the influence of climate change and b) NDVI under the influence of human activities. 
the climate has played an important role in promoting vegetation growth in the ECDZB in recent years.

\section{Characteristics of Vegetation Change under the Influence of Human Activities}

Fig. 7b) reveals the trend in the $\mathrm{NDVI}_{\mathrm{R}}$ changes, which reflects the trend of the NDVI under the influence of human activities. It can be seen that the $\mathrm{NDVI}_{\mathrm{R}}$ in the study area showed an increasing trend in general, and the northeastern area experienced the most obvious increase. The area of vegetation improved because of human activities accounting for $75.13 \%$ of the total study area, which was slightly lower than the proportion of area with the actual vegetation improvements. The areas where human activities led to a decrease in NDVI accounted for $24.87 \%$ of the total area, and these areas were mainly distributed in regions with cultivated land and artificial surfaces in each district; thus, the results are mostly consistent with the distribution of areas with degraded vegetation shown in Fig. 5. The analysis above shows that human activities also played an important role in promoting the vegetation situation in the ECDZB from 2001 to 2015.

\section{Relative Contributions of Climate Change and Human Activities to Vegetation Variations}

According to the calculation formulas listed in Table 1, the relative contributions of climate change and human activities to changes in vegetation cover under different scenarios were calculated based on the trends in the $\mathrm{NDVI}_{O}, \mathrm{NDVI}_{\mathrm{P}}$ and $\mathrm{NDVI}_{\mathrm{R}}$, and the final results (Fig. 8) were combined with the division from the development, protection, control and construction of the Beijing mountainous area guide plan map. Overall, the relative contribution rates of climate change and human activities were $40.34 \%$ and $59.66 \%$, respectively, and the area where human activities were dominant (i.e., the relative contribution rate was greater than $50 \%$ ) accounted for $75.90 \%$; this result indicates that human activities were the main factor driving the dynamics of vegetation cover in the study area over a 15 -year period. It can be seen in Fig. 8 that the contribution rates of human activities to vegetation variations tended to be highest in the eastern part, and the rates gradually decreased from east to west; correspondingly, the contribution rates of climate change tended to increase from east to west. The regions with high relative contribution rates of climate change are mainly located in the deep mountain areas, while the regions with high relative contribution rates of human activities are mainly distributed in the flat areas of the west, the shallow mountain areas and the plain areas in the eastern part of the ECDZB. In contrast with the land cover data, we found that in the artificial surfaces and cultivated areas that are located in the eastern part of Mentougou District, the southwest part of Yanqing District and the southeast part of the ECDZB, the relative contribution a)

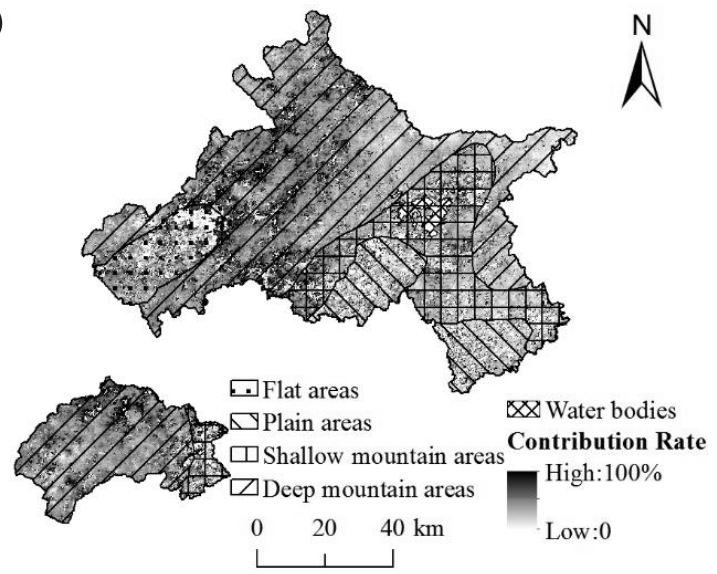

b)

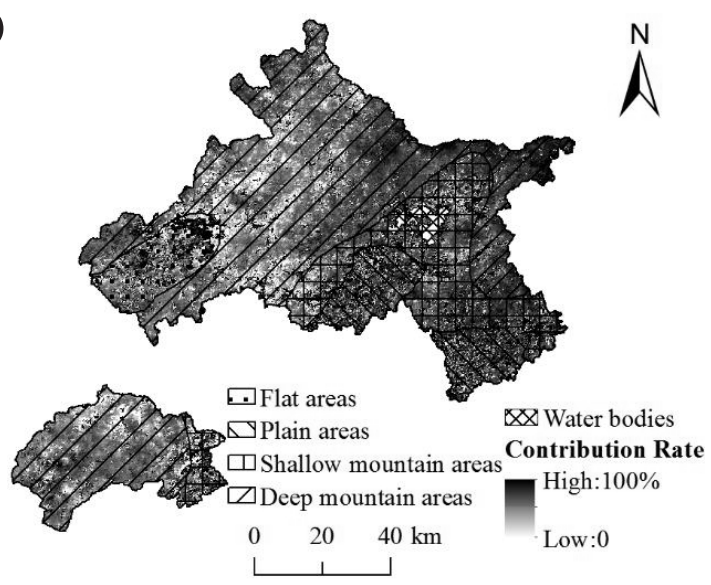

Fig. 8. Spatial distribution of the relative contribution of a) climate change and $b$ ) human activities to vegetation change in the ECDZB from 2001-2015.

rates of human activities are higher than those in the surrounding forests and grasslands. We also noticed that there are some strip-shaped regions in Huairou District and Yanqing District, whose climate contribution rates are extremely high. The reason for this phenomenon might be that these regions belong to Yanshan Mountain, where the growth of vegetation is more susceptible to climate factors, such as precipitation and temperature. In summary, we hypothesize that in deep mountain areas, which have higher altitudes and present inconvenient transportation, the land cover types are mainly forests and grasslands, and these areas have experienced little human activity, thus, the human activities that may have affected the change in vegetation cover are limited; therefore, vegetation growth in deep mountain areas is mainly affected by climate change. Human activities occur more frequently in the other areas of the ECDZB as a result of the lower elevation and land cover types, which are mainly cultivated lands and artificial surfaces; thus, in areas of the ECDZB outside of the deep mountain areas, it seems reasonable that human activities have a greater effect than climate variations on the processes related to changes in vegetation cover. 


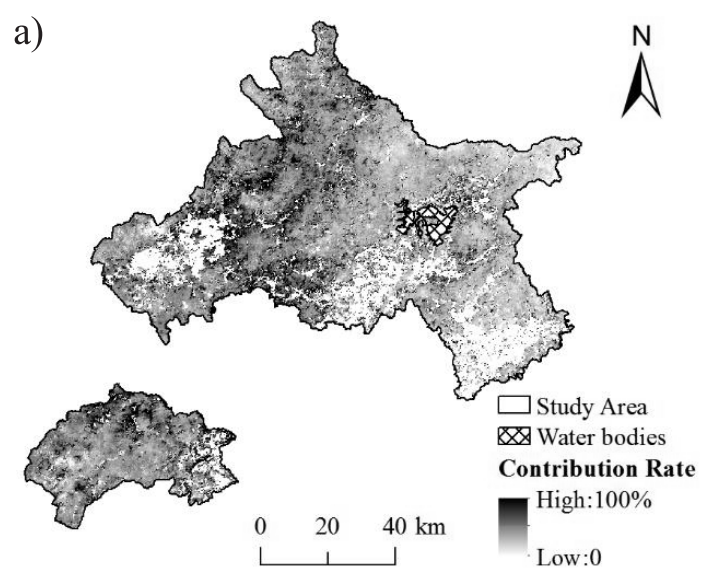

b)

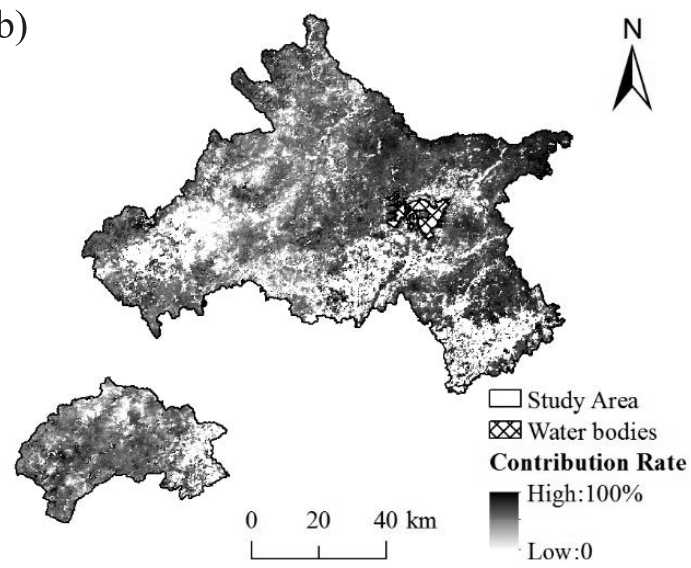

Fig. 9. Spatial distribution of the relative contribution of a) climate change and b) human activities in the vegetation improvement regions from 2001-2015.

The areas with improved and degraded vegetation in the study area were separated to analyze the respective relative contribution rates of climate change and human activities to changes in vegetation. Fig. 9 reflects the spatial distribution of the relative contribution rates in the areas with improved vegetation in the ECDZB between 2001 and 2015. The relative contribution rate of climate change in the areas with improved vegetation was $44.78 \%$ in general, and the relative contribution of human activities was $55.22 \%$ overall; these results indicate that the influence of human activities dominates the improvement processes in the areas with increased vegetation. The areas that were dominated by climate change accounted for $27.66 \%$, and these areas were centrally distributed in the northern part of Mentougou District and in the vicinity of Yanshan Mountain in the northwestern part of the study region. Furthermore, the areas dominated by human activities accounted for $72.34 \%$ and were widely distributed in the eastern and southwestern parts of the study area.

Fig. 10 shows the relative contributions of the two factors in the areas with degraded vegetation in the study area during 2001-2015. The relative contribution rate of climate change in the areas with degraded vegetation was $18.00 \%$ in general; moreover, the area dominated
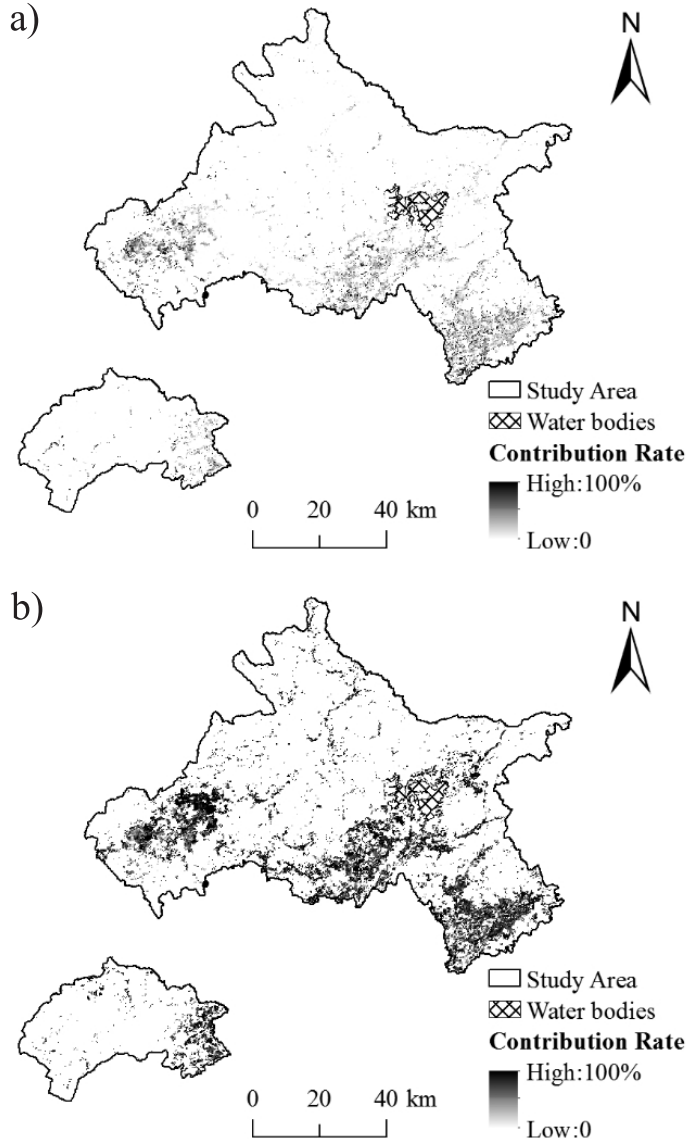

Fig. 10. Spatial distribution of the relative contribution of a) climate change and b) human activities in the vegetation degradation regions from 2001-2015.

by climate change accounted for only $6.89 \%$, and these areas were sporadically distributed in the regions that experienced decreased vegetation. The relative contribution rate of human activities was $82.00 \%$, and the area dominated by human activities accounted for 93.11\% and were widely distributed in the vegetation degradation zone; furthermore, the corresponding types of land cover were primarily cultivated land and artificial surfaces. These results indicate that during 2001-2015, unreasonable human activities were the main factors that led to vegetation degradation in the ECDZB.

\section{Discussion}

\section{Determining Driving Factors}

As an important basis of this study, the determination of the driving factors of vegetation change should be conducted with caution. Previous studies have shown that climate change and human activities are the main factors affecting vegetation change [35-36], and among the climate factors, temperature and precipitation are the most important factors influencing changes in the NDVI [37]. In addition, human activities, 
such as environmental protection policies, ecological construction projects and management measures, have important impacts on the dynamic changes in vegetation [38]. Therefore, we proposed that climate change and human activities are the main factors affecting the change in vegetation cover in the ECDZB, which is mainly composed of mountainous areas. Based on the discussion above, we only considered climatic and human factors in the calculation of relative contributions, and we also analyzed the partial correlations between NDVI variations and the driving factors except for human activities, which are complex and difficult to quantify [22].

\section{Spatial Heterogeneity of Vegetation Cover}

This research found that from the temporal perspective, the condition of vegetation cover in the ECDZB has generally improved from 2001 to 2015, which is consistent with the results of previous research $[19,39]$. Based on the Landsat Thematic Mapper (TM) and Operational Land Imager (OLI) images, Jiang et al. [40] concluded that the vegetation situation in Beijing was improving overall between 2000 and 2015, with only small areas having deteriorated. In terms of spatial scale, our results indicated that the vegetation cover change in the ECDZB was spatially heterogeneous. The areas of increase were mainly forests and grasslands that were widely distributed in large mountainous areas, while the areas of decrease were clustered in densely populated areas, such as the cultivated lands and artificial surfaces that are distributed in the plain areas and the flat areas. In addition, the areas belonging to these cover types are usually regular in shape and more concentrated in distribution; thus, the areas that decreased can be characterized by clusters.

\section{Separating the Effects of Driving Factors on Vegetation Cover}

Separating the effects of climate change and human activities on vegetation cover shows that between 2001 and 2015, the annual maximum NDVI of the ECDZB showed overall increasing trends under the respective influences of climate change and human activities, and these results indicate that, in general, these two factors both played important roles in promoting vegetation improvement in the study area. Under the single influence of climate change, $85.65 \%$ of the total area displayed an increasing trend for the NDVI, and it reached its highest rate in the western part of the study area; in contrast, the areas that experienced decreases were concentrated in the cultivated lands and artificial surfaces of Yanqing District, Huairou District and Pinggu District. Under the impact of human activities, the vegetation degradation area accounted for $24.87 \%$ and was mainly distributed in the middle of Yanqing District, the eastern part of Mentougou District, and the southern parts of Huairou District, Pinggu District, and Miyun District; moreover, in these areas, the corresponding land cover types were mainly cultivated land and artificial surfaces, i.e., the urban areas of each district, indicating that urban expansion negatively impacted the improvement of vegetation cover in general. Most areas in the ECDZB showed increasing trends in the NDVI under the influence of human activities, and the NDVI of forests and grasslands in the northeast part of Miyun District increased the fastest. This result was indistinguishable from the measures taken by the government of the Miyun District in recent years, including the establishment of the "six protection" mechanisms for protecting water, rivers, mountains, forests, land and the environment, and the implementation of the comprehensive remediation of the surrounding environment of Miyun Reservoir, BeijingTianjin sand source control project, small watershed management, and mine pit vegetation restoration.

\section{Characteristics of the Relative Contributions of the Driving Factors}

The calculated results of the relative contributions of climate change and human activities to vegetation change under different scenarios showed that the relative contribution of human activities was greater than that of climate change in general, and the regions with a high relative contribution rate of human activities were mainly distributed in the shallow mountain areas, the plain areas and the flat areas. The regions where climate change dominated the vegetation variations were mainly distributed in the deep mountain areas, which were most likely related to the fact that little human activity occurs here. The impact of human activities was dominant in the process of vegetation change in both the areas that increased and the areas that decreased. Different human activities have distinct influences on vegetation change. Among these activities, some, such as afforestation, are beneficial to vegetation growth, while others such as urban expansion are generally not conducive to vegetation growth; therefore, human activities are of great significance in terms of improving the vegetation cover condition. Since the establishment of the ECDZB, the governments of the relevant districts have launched positive explorations to improve the ecological environment, e.g., the ecological restoration of abandoned mines, the remediation of river ditches, the construction of parks, and the implementation of the Beijing-Tianjin sand source control project [8, 19]. These measures have made significant contributions to the improvement of vegetation cover, indicating that the establishment of the ECDZB has achieved remarkable results and has effectively promoted the improvement and development of the regional ecological environment.

\section{Limitations and Prospects}

Though the NDVI has been used widely to reflect vegetation cover conditions [41-44], it has some 
shortcomings. The NDVI is sensitive to changes in the soil background, and when applied to places with high vegetation coverage, its sensitivity to vegetation will decrease considerably; moreover, it is also prone to supersaturation [45-46]. The land cover types in the ECDZB are mainly forest, cultivated land and grassland; therefore, the selection of NDVI as the indicator of vegetation cover in this paper may influence the accuracy of the results. Human activities are complex and diverse; therefore, we considered human activities as one general factor and did not analyze the contribution rates of specific human activities or their correlations with the driving factors. Climate factors, such as temperature and precipitation, play key roles in vegetation growth, and their effects may not immediately appear in general, which indicates that the response displays hysteresis. In this study, we analyzed the vegetation change only at the interannual scale, and we did not consider the lag of the influence. The current study was limited to the overall situation in terms of the analysis of vegetation changes, and the perspective of different vegetation types was not analyzed; thus, this may be a topic that can be explored in future studies.

\section{Conclusions}

Using a combination of the MODIS NDVI time series data of the ECDZB from 2001 to 2015 and the data from 30 meteorological stations, the spatiotemporal variation in vegetation cover and its driving factors were analyzed; after that, the effects of climate change and human activities on vegetation changes were further separated and quantitatively analyzed. The main conclusions are as follows:

1) Over a 15 -year period, the annual precipitation in the ECDZB showed an upward trend, while the average annual temperature showed a decreasing trend, and the annual maximum NDVI showed a general increasing trend. The total vegetation improvement area accounted for $82.69 \%$ of the total study area, and these areas were mainly distributed in mountainous forest; whereas the total vegetation degradation areas accounted for $17.31 \%$ and were mainly concentrated in the cultivated land and artificial surfaces of the middle Yanqing District, southern Pinggu District, southern Huairou District, southern Miyun District and the eastern part of Mentougou District. Specifically, the areas with slight increases in vegetation cover accounted for $60.98 \%$ of the total area, which was the highest proportion among all the changing degrees mentioned in this research, whereas the areas with severely decreased vegetation cover accounted for the smallest proportion, at only $2.34 \%$.

2) The annual maximum NDVI of the ECDZB was positively correlated with the annual precipitation in general, the positively correlated area accounted for $87.66 \%$ of the total area, and the partial correlation coefficient reached the highest value in the north. The annual maximum NDVI was negatively correlated with the average annual temperature in general, and the negatively correlated areas were mainly distributed in the north and south. The partial correlation coefficients between NDVI and precipitation and temperature that passed the test of $\mathrm{p}<0.05$ accounted for $13.03 \%$ and $5.46 \%$, respectively. These results indicated that, in general, precipitation played an active role in vegetation cover change in the ECDZB from 2001 to 2015, while the average annual temperature was not conducive to the increase in the annual maximum NDVI in the study area when the value was too high.

3) During the 15-year study period, the effects of climatic and human factors on the change in vegetation cover were both positive, and the relative contribution of human activities to the process of vegetation cover change was $59.66 \%$, which was greater than the value of $40.34 \%$ for climate change. The contributions of human activities were dominant in both the vegetation improvement and the vegetation degradation areas, indicating that human activities were the main factors driving changes in vegetation. Based on a combination of the results, the land cover data and the partition situation of the ECDZB, it can be concluded that, in areas with a dense population distribution, frequent human activities, and low elevation, the relative contribution of human activities to vegetation change is higher, whereas in mountainous areas, changes in vegetation are more susceptible to climate change. The overall vegetation cover situation improved in the study area over the 15-year study period, and this improvement was inextricably linked with the establishment of the ECDZB in 2005 and a series of ecological protection measures taken by the government. These results indicate that the establishment of the ECDZB played an extremely important role in improving vegetation cover during the period of 2001-2015.

\section{Acknowledgements}

This study was supported by the National Natural Science Foundation of China (41877533) and the Beijing Social Science Foundation (18GLB014).

\section{Conflicts of Interest}

The authors declare no conflict of interest.

\section{References}

1. GODINEZ-ALVAREZ H., HERRICK J.E., MATTOCKS M., TOLEDO D., ZEE J.V. Comparison of three vegetation monitoring methods: their relative utility for ecological assessment and monitoring. Ecol. Indic., 9 (5), 1001, 2009.

2. PENG J., LIU Z.H., LIU Y.H., WU J.S., HAN Y.N. Trend analysis of vegetation dynamics in Qinghai-Tibet Plateau using Hurst Exponent. Ecol. Indic., 14, 28, 2012. 
3. LIU Y., LI Y., LI S.C., MOTESHARREI S. Spatial and temporal patterns of global NDVI trends: correlations with cimate and human factors. Remote Sens., 7, 13233, 2015.

4. YUE Y.M., WANG K.L., ZHANG B., CHEN Z.C., JIAO Q.J., LIU B., CHEN H.S. Exploring the relationship between vegetation spectra and eco-geo-environmental conditions in Karst region, Southwest China. Environ. Monit. Assess., 160, 157, 2010.

5. WESSELS K.J., PRINCE S.D., MALHERBE J., SMALL J., FROST P.E., VANZYL D. Can human-induced land degradation be distinguished from the effects of rainfall variability? A case study in South Africa. J. Arid. Environ., 68, 271, 2007.

6. BOSCHETTI M., NUTINI F., BRIVIO P.A., BARTHOLOME E., STROPPIANA D., HOSCILO A. Identification of environmental anomaly hot spots in West Africa from time series of NDVI and rainfall. ISPRS-J. Photogramm. Remote Sens., 78, 26, 2013.

7. NING T.T., LIU W.Z., LIN W., SONG X.Q. NDVI variation and its responses to climate change on the northern Loess Plateau of China from 1998 to 2012. Adv. Meteorol., 2015, 725427, 2015.

8. ECKERT S., HUSLER F., LINIGER H., HODEL E. Trend analysis of MODIS NDVI time series for detecting land degradation and regeneration in Mongolia. J. Arid. Environ., 113, 16, 2015.

9. REED B.C., BROWN J.F., VANDERZEE D., LOVELAND T.R., MERCHANT J.W., OHLEN D.O. Measuring phonological variability from satellite imagery. J. Veg. Sci., 5 (5), 703, 1994.

10. DAHAM A., HAN D.W., RICO-RAMIREZ M., MARSH A. Analysis of NVDI variability in response to precipitation and air temperature in different regions of Iraq, using MODIS vegetation indices. Environ. Earth Sci., 77, 389, 2018.

11. ZOUNGRANA B.J.B., CONRAD C., THIEL M., AMEKUDZI L.K., DA E.D. MODIS NDVI trends and fractional land cover change for improved assessments of vegetation degradation in Burkina Faso, West Africa. J. Arid. Environ., 153, 66, 2018.

12. HUA W.J., CHEN H.S., ZHOU L.M., XIE Z.H., QIN M.H., LI X., MA H.D., HUANG Q.H., SUN S.L. Observational quantification of climatic and human influences on vegetation greening in China. Remote Sens., 9, 425, 2017.

13. YAN L.B., HE R.X., KAŠANIN-GRUBIN M., LUO G.S., PENG H., QIU J.X. The dynamic change of vegetation cover and associated driving forces in Nanxiong Basin, China. Sustainability, 9, 443, 2017.

14. KANG C., ZHANG Y.L., WANG Z. F., LIU L.S., ZHANG H.M., JO Y. The driving force analysis of NDVI dynamics in the Trans-Boundary Tumen River Basin between 2000 and 2015. Sustainability, 12, 2350, 2017.

15. ZHAO L., DAI A.G., DONG B. Changes in global vegetation activity and its driving factors during 19822013. Agric. For. Meteorol., 249, 198, 2018.

16. FARAMARZI M., HEIDARIZADI Z., MOHAMADI A., HEYDARI M. Detection of vegetation changes in relation to Normalized Difference Vegetation Index (NDVI) in Semi-Arid Rangeland in Western Iran. J. Agric. Sci. Technol., 20, 51, 2018.

17. LEROUX L., BEGUE A., SEEN D.L., JOLIVOT A., KAYITAKIRE F. Driving forces of recent vegetation changes in the Sahel: Lessons learned from regional and local level analyses. Remote Sens. Environ., 191, 38, 2017.

18. MURIITHI F.K., YU D.L., ROBILA S. Vegetation response to intensive commercial horticulture and environmental changes within watersheds in central highlands, Kenya, using AVHRR NDVI data. GISci. Remote Sens., 53 (1), 1, 2016.

19. LIU J.H., WU J.J., WU Z.T., LIU M. Response of NDVI dynamics to precipitation in the Beijing-Tianjin sandstorm source region. Int. J. Remote Sens., 34, 5331, 2013.

20. ZHOU T.Y., AKIYAMA T., HORITA M., KHARRAZI A., KRAINES S., LI J., YOSHIKAWA K. The impact of ecological restoration projects in dry lands: Data-based assessment and human perceptions in the lower reaches of Heihe River Basin, China. Sustainability, 10, 1471, 2018.

21. TONG X.W., WANG K.L., YUE Y.M., BRANDT M., LIU B., ZHANG C.H., LIAO C.J., FENSHOLT R. Quantifying the effectiveness of ecological restoration projects on longterm vegetation dynamics in the karst regions of Southwest China. Int. J. Appl. Earth Obs. Geoinf., 54, 105, 2017.

22. HUANG K., ZHANG Y.J., ZHU J.T., LIU Y.J., ZU J.X., ZHANG J. The influences of climate change and human activities on vegetation dynamics in the Qinghai-Tibet Plateau. Remote Sens., 8, 876, 2016.

23. LIANG F.C., LIU L.M., QU Y.B., SHUANG W.Y. Planning methodology of agricultural landscape and its application in ecological conservation development area. Transactions of the Chinese Society of Agricultural Engineering, 30, 286, 2014 [In Chinese].

24. SUN C., LIU Y., TANG X.M., REN Y.M. The choice of leading industry based on functional orientation in the ecological conservation development area of Beijing. Acta Scientiarum Naturalium Universitatis Pekinensis, 52, 1085, 2016 [In Chinese].

25. LI Y.Y. The implementation approaches and policies and measures of ecological compensation mechanism for Beijing ecological conservation districts. Journal of Central University of Finance \& Economics, 12, 75, 2011 [In Chinese].

26. HE D.S., LIU H., XUE Z.Q. Studies on the development of rural tourism of Beijing ecological conservation development area. Chinese Journal of Agricultural Resources and Regional Planning, 31, 43, 2010 [In Chinese].

27. ZHANG L. Beijing mountain functional zoning and relative policies. Economic Geography, 29, 989, 2009 [In Chinese].

28. HOLBEN B.N. Characteristics of maximum-value composite images from temporal AVHRR data. Int. J. Remote Sens., 7, 1417, 1986.

29. The development, protection, control and construction of the Beijing mountainous area guide plan map. Available online: http://www.bjghy.com.cn/ (accessed on 10 March 2018).

30. LIU X.F., ZHU X.F., LI S.S., LIU Y.X., PAN Y.Z. Changes in growing season vegetation and their associated driving forces in China during 2001-2012. Remote Sens., 7, 15517, 2015.

31. ZHU W., LI S. The dynamic response of forest vegetation to hydrothermal conditions in the Funiu Mountains of western Henan Province. J. Geogr. Sci., 27, 565, 2017.

32. MU S.J., YANG H.F., LI J.L., CHEN Y.Z., GANG C.C., ZHOU W., JU W.M. Spatio-temporal dynamics of vegetation coverage and its relationship with climate factors in Inner Mongolia, China. J. Geogr. Sci., 23, 231, 2013.

33. EVANS J., GEERKEN R. Discrimination between climate and human-induced dryland degradation. J. Arid. Environ., 57, 535, 2004. 
34. HE C.Y., TIAN J., GAO B., ZHAO Y.Y. Differentiating climate-and human-induced drivers of grassland degradation in the Liao River Basin, China. Environ. Monit. Assess., 187, 4199, 2015.

35. SUN Y., YANG Y.L., ZHANG L., WANG Z.L. The relative roles of climate variations and human activities in vegetation change in North China. Phys. Chem. Earth., 87-88, 67, 2015.

36. ZHANG Y., ZHANG C.B., WANG Z.Q., CHEN Y.Z., GANG C.C., AN R., LI, J.L. Vegetation dynamics and its driving forces from climate change and human activities in the Three-River Source Region, China from 1982 to 2012. Sci. Total Environ., 563, 210, 2016.

37. LI H.D., LI Y.K., GAO Y.Y., ZOU C.X., YAN S.G., GAO J.X. Human impact on vegetation dynamics around Lhasa, Southern Tibetan Plateau, China. Sustainability, 8, 1146, 2016.

38. HAN G.F., YANG Y.C., YAN S.Y. Vegetation activity trend and its relationship with climate change in the Three Gorges Area, China. Adv. Meteorol., 2013, 235378, 2013.

39. JING X., YAO W.Q., WANG J.H., SONB, X.Y. A study on the relationship between dynamic change of vegetation coverage and precipitation in Beijing's mountainous areas during the last 20 years. Math. Comput. Model., 54, 1079, 2011.

40. JIANG M.C., TIAN S.F., ZHENG Z.J., ZHAN Q., HE Y.X. Human activity influences on vegetation cover changes in
Beijing, China, from 2000 to 2015. Remote Sens., 9, 271, 2017.

41. ESTEL S., KUEMMERLE T., ALCANTARA C., LEVERS C., PRISHCHEPOV A., HOSTERT P. Mapping farmland abandonment and recultivation across Europe using MODIS NDVI time series. Remote Sens. Environ., 163, 312, 2015.

42. HELMAN D., LENSKY I.M., TESSLER N., OSEM Y. A phenology-based method for monitoring woody and herbaceous vegetation in Mediterranean forests from NDVI time series. Remote Sens., 7, 12314, 2015.

43. ZOUNGRANA B.J.B., CONRAD C., THIEL M., AMEKUDZI L.K., DA E.D. MODIS NDVI trends and fractional land cover change for improved assessments of vegetation degradation in Burkina Faso, West Africa. J. Arid. Environ., 153, 66, 2018.

44. BUJALSKY L., JIRKA V., ZEMEK F., FROUZ J. Relationships between the normalised difference vegetation index and temperature fluctuations in postmining sites. Int. J. Min. Reclam. Environ., 32, 254, 2018.

45. CARLSON T.N., RIPLEY D.A. On the relation between NDVI, fractional vegetation cover, and leaf area index. Remote Sens. Environ., 62, 241, 1997.

46. JIAPAER G., CHEN X., BAO A.M. A comparison of methods for estimating fractional vegetation cover in arid regions. Agric. For. Meteorol., 151, 1698, 2011. 
